\title{
Phosphorylated AKT expression in tumor-adjacent normal tissue is associated with poor prognosis in patients with hepatocellular carcinoma
}

\author{
YAO-LI CHEN ${ }^{1-3}$, PO-MING CHEN ${ }^{4}$, YING-ZI MING $^{3}$, PING-YI LIN ${ }^{2}, \mathrm{CHIH}^{-P I N G ~ \mathrm{CHU}^{5,6^{*}} \text { and PEI-YI CHU }}{ }^{5-7^{*}}$
}

${ }^{1}$ School of Medicine, Kaohsiung Medical University, Kaohsiung 80708; ${ }^{2}$ Department of General Surgery, Changhua Christian Hospital, Changhua 50008, Taiwan, R.O.C.; ${ }^{3}$ Transplantation Center, Third Xiangya Hospital of

Central South University, Changsha, Hunan 410013, P.R. China; ${ }^{4}$ Research Assistant Center; ${ }^{5}$ Department of Pathology,

Show Chwan Memorial Hospital, Changhua 50008; ${ }^{6}$ School of Medicine, College of Medicine, Fu-Jen Catholic University, New Taipei 24205; ${ }^{7}$ National Institute of Cancer Research, National Health Research Institutes, Tainan 70456, Taiwan, R.O.C.

Received April 21,2016; Accepted June 23, 2017

DOI: $10.3892 / \mathrm{ol} .2017 .7137$

\begin{abstract}
The AKT pathway serves important roles in tumor cell growth. Its overexpression is associated with poor prognosis in a number of types of cancer; however, the role of AKT in the role of the pathogenesis of hepatocellular carcinoma (HCC) remains unclear. The present study was undertaken to explore the clinical relevance of phosphorylated AKT (p-AKT) in HCC. The level of p-AKT in tumor (TU) and paired adjacent normal liver (AN) tissue from $202 \mathrm{HCC}$ patients was evaluated with immunohistochemistry. The results demonstrated that p-AKT was more highly expressed in TU than in AN tissue. Kaplan-Meier curves and Cox regression revealed that patients with a high expression of p-AKT (AN) exhibited reduced overall and relapse-free survival times; this was not observed at a statistically significant level in p-AKT (TU). Additionally, the high expression of p-AKT (AN) was positively correlated with hepatitis $\mathrm{C}$ virus (HCV) infection in HCC patients. These results support the hypothesis that AKT activation is a mechanism of $\mathrm{HCV}$-induced hepatocarcinogenesis, suggesting that AKT can be a therapeutic target for the treatment of recurrent HCC subsequent to surgical resection.
\end{abstract}

Correspondence to: Dr Chih-Ping Chu or Dr Pei-Yi Chu, Department of Pathology, Show Chwan Memorial Hospital, 542, Section 1, Chung-Shang Road, Changhua 50008, Taiwan, R.O.C.

E-mail: happffl@yahoo.com.tw

E-mail: chu.peiyi@msa.hinet.net

*Contributed equally

Key words: phosphorylated AKT, poor prognosis, hepatocellular carcinoma, normal tissue

\section{Introduction}

Hepatocellular carcinoma (HCC) is the seventh most commonly diagnosed cancer and the sixth leading cause of cancer-associated mortality worldwide (1). It is generally more common in non-Caucasian populations (1). Chronic infection with hepatitis B virus (HBV) or hepatitis C virus (HCV), alcoholic liver disease and non-alcoholic fatty liver disease have been associated with the tumorigenesis of HCC (2). HCC is an inflammation-associated cancer that generally develops in the background of chronic hepatitis, regardless of the triggering etiology (3).

Inflammation-induced $\mathrm{HCC}$ is dependent on AKT activation $(4,5)$. AKT, also called protein kinase B, is a serine/threonine kinase. Phosphorylated AKT (p-AKT), the active form of AKT, influences a range of cellular functions, including cell growth, proliferation, differentiation, motility, survival and intracellular trafficking (6). Previous studies have indicated that the increased immunohistochemical expression of p-AKT is correlated with a poorer prognosis in various types of cancer, including endometrial carcinoma (7), renal cell carcinoma (8), colorectal cancer (9), breast cancer (10), melanoma (11) and nasopharyngeal carcinoma (12). In HCC, the upregulation of AKT1, 2 or 3 has been demonstrated to be significantly associated with tumor progression and a poor survival rate (13).

p-AKT may be a target for therapeutic regimens aiming to reverse acquired resistance to sorafenib during the treatment of patients with HCC (14-16). Although p-AKT expression in tumor tissue (TU) was previously explored (13), the role for p-AKT in the adjacent non-neoplastic liver tissue (AN) remains unidentified. The aim of the present study was to apply immunohistochemical staining for p-AKT to clinical samples of TU and AN tissues, to investigate the clinical significance in patients with $\mathrm{HCC}$.

\section{Patients and methods}

Patients. Formalin-fixed and paraffin-embedded HCC TU and paired AN samples were obtained from 202 patients 
that underwent surgical tumor resection at Changhua Christian Hospital, (Changhua, Taiwan) between July 2011 and November 2013. In the retrospective the study, clinical data was obtained through chart review, thus, patients lost in the follow-up period were excluded. All patients received chemotherapy or radiotherapy prior to surgery. A tissue microarray (TMA) was constructed from the TU and AN tissues. A TMA block was made up of 96 tissue cores measuring $2 \mathrm{~mm}$ in diameter. Approximately 250 consecutive sections (4- $\mu \mathrm{m}$ thick) could be cut from a TMA block and used for immunohistochemical staining to determine specific protein expression patterns for antibodies. All patients were staged as per the American Joint Committee on Cancer staging guidelines (17). Each patient's clinical characteristics and outcomes were collected until the event of patient mortality, censorship or loss of follow-up. The Ethics Committee of the Institutional Review Board of Changhua Christian Hospital approved all procedures of the present study. Informed consents were obtained from all sample donors in accordance with the Declaration of Helsinki.

The patients, including 56 females and 146 males, were aged 29-81 years (mean \pm standard deviation, 63.1 \pm 11.7 ) Survival time was defined as period from the date of primary surgery to the date of patient mortality or disease recurrence. Due to the retrospective nature of the study, clinical data was obtained through chart review, and some information was incomplete; among the $202 \mathrm{HCC}$ patients, HCV status was unknown for 8 and HBV serum antigen status was unknown for 7. The median follow-up time subsequent to surgery was 907 days; the median OS time of all patients was 937 days. A total of 44 patients succumbed to HCC during the study. On the basis of follow-up data, 8 patients relapsed, with local recurrence.

Immunohistochemistry (IHC) and scoring. IHC was used to detect $\mathrm{p}$-AKT protein expression. The IHC procedures were conducted as previously described (18), using an anti-p-AKT antibody (sc-16646-R) purchased from Santa Cruz Biotechnology, Inc. (Dallas, TX, USA). Negative controls were obtained by performing all IHC steps without the primary antibody. The IHC staining intensities were evaluated by a board-certified pathologist. Immunostaining scores were defined as the cell staining intensity (nil, 0; weak, 1; moderate, 2; strong, 3) multiplied by the percentage of labeled cells $(0-100 \%)$, producing scores between 0-300. A score greater than the mean was defined as 'high' immunostaining, whereas a score less than or equal to the mean was categorised as 'low', respectively for AN and TU tissues.

Statistical analysis. All statistics were performed with SPSS software (version 18.0; SPSS, Inc., Chicago, IL, USA). $\chi^{2}$ analyses and paired t-tests were used to analyze the associations between clinical characteristics and p-AKT expression. Survival curves were plotted using the Kaplan-Meier method and variables associated with survival were analyzed with Cox's proportional hazards regression model. Statistical differences in survival data were analyzed using the log-rank test. $\mathrm{P}<0.05$ was considered to indicate a statistically significant difference.

\section{Results}

p-AKT expression is higher in TU than in AN. A total of 202 HCC patients were enrolled in the present study. p-AKT expression was detected using IHC in 202 sets of paired TU and AN tissues (Fig. 1). p-AKT expression level in TU tissue (p-AKT TU) was significantly higher than in the paired AN tissue (p-AKT AN; P<0.001; Fig. 2). The mean IHC score was 179 for TU and 81 for AN; these scores were used as cut-off values for high and low expression in the respective groups.

p-AKT (AN) is positively associated with hepatitis c virus infection. Statistical analysis was performed to verify whether p-AKT (AN) and p-AKT (TU) were linked with clinicopathological parameters including age, sex, differentiation grade, tumor stage, HBV surface antigen and HCV status. Only HCV status was significantly associated with p-AKT (AN); Patients with HCC that exhibited HCV infection had a higher expression of p-AKT (AN) than those without HCV infection $(\mathrm{P}=0.026$; Table I). The results of the present study suggest that the effect of HCV infection on p-AKT (AN) expression was more evident than on $\mathrm{p}-\mathrm{AKT}$ (TU).

p-AKT (AN) is associated with OS and RFS time in HCC patients. The association of p-AKT (AN) and clinicopathological parameters, including age, sex, differentiation, stage, HBV surface antigen, HCV, p-AKT (TU) and p-AKT (AN), with patient survival time was investigated by univariate analysis The full results are included in Table II. OS time was significantly associated with stage $(\mathrm{P}<0.001)$ and $\mathrm{p}-\mathrm{AKT}$ (AN) $(\mathrm{P}=0.011)$; RFS was significantly associated with stage $(\mathrm{P}<0.001)$ and $\mathrm{p}-\mathrm{AKT}(\mathrm{AN})(\mathrm{P}=0.050)$. It was then examined whether p-AKT (AN) expression was associated with clinical outcomes in HCC patients. Kaplan-Meier analysis demonstrated that patients with high p-AKT (AN) had shorter OS and RFS periods when compared with patients with low p-AKT (AN) ( $\mathrm{P}=0.011$ and $\mathrm{P}=0.050$, respectively; Table II; Fig. 3), whereas p-AKT (TU) was not significantly associated with survival time. Cox regression analysis indicated a prognostic significance for p-AKT (AN) in OS and RFS in the study population ( $\mathrm{P}=0.011$ and $\mathrm{P}=0.046$, respectively; Table III). The hazard ratios for high p-AKT (AN) were 2.192 for OS and 1.751 for RFS, respectively, relative to low p-AKT (AN) (Table III). Additionally, the hazard ratios for stage III/IV were 3.064 for OS and 3.536 for RFS, respectively, relative to stage I/II (both $\mathrm{P}<0.001$; Table III). The results suggest that p-AKT (AN) expression may promote tumor malignancy, resulting in poor outcomes for patients with HCC.

\section{Discussion}

Based on the data of the present study, post-resection patients with HCV-associated HCC exhibit higher p-AKT (AN) expression than those without $\mathrm{HCV}$ infection. $\mathrm{p}-\mathrm{AKT}$ (AN) may be a predictor for prognosis and recurrence in HCC. These results support a previous study in which patients positive for $\mathrm{HCV}$ undergoing the resection of HCC experienced reduced OS and RFS times relative to patients negative for HCV (19). HCV is a single-stranded, positive-sense RNA virus of the Flaviviridae family; $\mathrm{HCV}$-induced $\mathrm{HCC}$ is expected to increase in the next 
Table I. Association of clinical parameters with p-AKT expression of AN and TU tissue in hepatocellular carcinoma patients.

\begin{tabular}{|c|c|c|c|c|c|c|c|}
\hline \multirow[b]{2}{*}{ Variables } & \multirow[b]{2}{*}{ Total, n (\%) } & \multicolumn{2}{|c|}{$\mathrm{p}-\mathrm{AKT}(\mathrm{AN}), \mathrm{n}(\%)$} & \multirow[b]{2}{*}{ P-value } & \multicolumn{2}{|c|}{ p-AKT (TU), n (\%) } & \multirow[b]{2}{*}{ P-value } \\
\hline & & Low & High & & Low & High & \\
\hline Total & 202 & 119 & 83 & & 115 & 87 & \\
\hline Age, years & & & & 0.424 & & & 0.764 \\
\hline$<65$ & $109(54)$ & $67(62)$ & $42(38)$ & & $61(56)$ & $48(44)$ & \\
\hline$\geq 65$ & $93(46)$ & $52(56)$ & $41(44)$ & & $54(58)$ & $39(42)$ & \\
\hline Sex & & & & 0.111 & & & 0.360 \\
\hline Female & $56(28)$ & $28(50)$ & $28(50)$ & & $29(52)$ & $27(48)$ & \\
\hline Male & $146(72)$ & $91(62)$ & $55(38)$ & & $86(59)$ & $60(41)$ & \\
\hline Differentiation & & & & 0.590 & & & 0.164 \\
\hline Well & $11(5)$ & $8(73)$ & $3(27)$ & & $9(81)$ & $2(19)$ & \\
\hline Moderate & $101(50)$ & $62(61)$ & $39(39)$ & & $60(59)$ & $41(41)$ & \\
\hline Poor & $84(42)$ & $46(55)$ & $38(45)$ & & $44(52)$ & $40(48)$ & \\
\hline Undifferentiated & $6(3)$ & $3(50)$ & $3(50)$ & & $2(33)$ & $4(67)$ & \\
\hline Stage & & & & 0.938 & & & 0.369 \\
\hline $\mathrm{I}, \mathrm{II}$ & $166(82)$ & $98(59)$ & $68(41)$ & & $97(58)$ & $69(42)$ & \\
\hline III, IV & $36(18)$ & $21(58)$ & $15(42)$ & & $18(50)$ & $18(50)$ & \\
\hline Hepatitis B surface antigen status & & & & 0.386 & & & 0.818 \\
\hline Negative & $89(44)$ & $55(62)$ & $34(38)$ & & $51(57)$ & $38(43)$ & \\
\hline Positive & $106(52)$ & $59(56)$ & $47(44)$ & & $59(56)$ & $47(44)$ & \\
\hline Unknown & $7(4)$ & $5(71)$ & $2(29)$ & & $5(71)$ & $2(29)$ & \\
\hline Hepatitis $C$ virus & & & & 0.026 & & & 0.520 \\
\hline Negative & $125(62)$ & $82(66)$ & $43(34)$ & & $73(58)$ & $52(42)$ & \\
\hline Positive & $69(34)$ & $34(49)$ & $35(51)$ & & $37(54)$ & $32(44)$ & \\
\hline Unknown & $8(4)$ & $3(38)$ & $5(62)$ & & $5(62)$ & $3(38)$ & \\
\hline
\end{tabular}

p-AKT, phosphorylated AKT; AN, adjacent normal liver; TU, tumor.
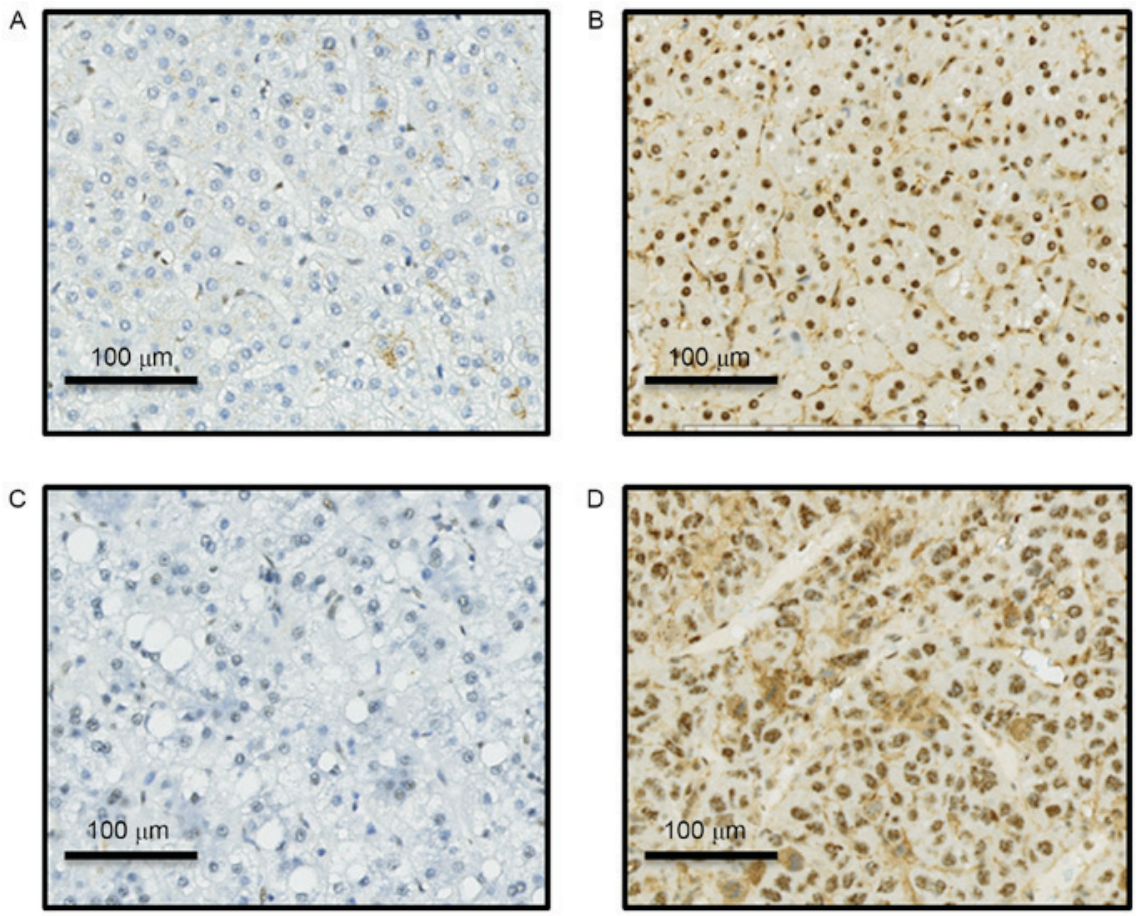

Figure 1. Immunohistochemical staining for phosphorylated AKT Representative images for (A) weak expression in AN tissue; (B) strong expression in AN tissue; (C) weak expression in TU tissue; (D) strong expression in TU tissue. Magnification, x100. AN, adjacent normal liver; TU, tumor. 
Table II. Univariate analysis of influences of clinical characteristics, and p-AKT (AN) or (TU), on OS and RFS in hepatocellular carcinoma patients.

\begin{tabular}{|c|c|c|c|c|c|c|c|}
\hline \multirow[b]{2}{*}{ Characteristics } & \multirow[b]{2}{*}{ Total, $\mathrm{n}$} & \multicolumn{2}{|c|}{ OS } & \multirow[b]{2}{*}{$\begin{array}{l}\text { Log-rank } \\
\text { P-value }\end{array}$} & \multicolumn{2}{|c|}{ RFS } & \multirow[b]{2}{*}{$\begin{array}{c}\text { Log-rank } \\
\text { P-value }\end{array}$} \\
\hline & & $\begin{array}{c}\text { Median } \\
\text { time (days) }\end{array}$ & Rate $(\%)$ & & $\begin{array}{c}\text { Median } \\
\text { time (days) }\end{array}$ & Rate $(\%)$ & \\
\hline Age, years & & & & 0.178 & & & 0.174 \\
\hline$<65$ & 109 & 923 & 81.7 & & 912 & 78.0 & \\
\hline$\geq 65$ & 93 & 874 & 74.2 & & 874 & 69.9 & \\
\hline Sex & & & & 0.635 & & & 0.445 \\
\hline Female & 56 & 838 & 76.8 & & 838 & 71.4 & \\
\hline Male & 146 & 910 & 78.8 & & 905 & 75.3 & \\
\hline Differentiation & & & & 0.755 & & & 0.416 \\
\hline Well/Moderate & 112 & 884 & 78.6 & & 879 & 75.9 & \\
\hline Poor/Undifferentiated & 90 & 914 & 77.8 & & 908 & 72.2 & \\
\hline Stage & & & & $<0.001$ & & & $<0.001$ \\
\hline I, II & 165 & 923 & 82.4 & & 921 & 80.0 & \\
\hline III, IV & 36 & 685 & 58.3 & & 630 & 47.2 & \\
\hline Hepatitis B surface antigen & & & & 0.917 & & & 0.365 \\
\hline Negative & 89 & 884 & 77.5 & & 874 & 70.8 & \\
\hline Positive & 106 & 916 & 78.3 & & 946 & 76.4 & \\
\hline Hepatitis $\mathrm{C}$ virus & & & & 0.256 & & & 0.489 \\
\hline Negative & 125 & 907 & 76.0 & & 904 & 72.8 & \\
\hline Positive & 69 & 884 & 82.6 & & 874 & 76.8 & \\
\hline p-AKT (TU) & & & & 0.894 & & & 0.326 \\
\hline Low & 115 & 874 & 78.3 & & 868 & 77.2 & \\
\hline High & 87 & 912 & 78.2 & & 912 & 77.0 & \\
\hline p-AKT (AN) & & & & 0.011 & & & 0.050 \\
\hline Low & 119 & 923 & 84.0 & & 917 & 79.0 & \\
\hline High & 83 & 874 & 69.9 & & 874 & 67.5 & \\
\hline
\end{tabular}

OS, overall survival; RFS, recurrence-free survival; p-AKT (TU), phosphorylated AKT in tumor tissue; p-AKT (AN), phosphorylated AKT in adjacent normal liver tissue.

Table III. Cox regression analysis for the influence of stage and p-AKT (AN) on OS and RFS time in hepatocellular carcinoma patients.

\begin{tabular}{|c|c|c|c|c|c|c|c|c|}
\hline \multirow[b]{2}{*}{ Variables } & \multicolumn{4}{|c|}{ OS } & \multicolumn{4}{|c|}{ RFS } \\
\hline & HR & $95 \% \mathrm{CI}$ & $\begin{array}{c}\text { Unfavorable/ } \\
\text { favorable }\end{array}$ & P-value & HR & $95 \% \mathrm{CI}$ & $\begin{array}{l}\text { Unfavorable/ } \\
\text { favorable }\end{array}$ & P-value \\
\hline p-AKT (AN) & 2.192 & $1.193-4.026$ & High/low & 0.011 & 1.751 & $1.009-3.039$ & High/low & 0.046 \\
\hline Stage & 3.064 & $1.637-5.733$ & III, IV/I, II & $<0.001$ & 3.536 & $2.003-6.241$ & III, IV/I, II & $<0.001$ \\
\hline
\end{tabular}

p-AKT (AN), phosphorylated AKT in adjacent normal liver tissue; OS, overall survival; RFS, recurrence-free survival; HR, hazard ratio; CI, confidence interval.

two decades (20,21). Examinations of the association between HCV and the phosphatidylinositol-4,5-bisphosphate 3-kinase (PI3K)/AKT pathway has revealed that the $\mathrm{HCV}$-associated NS5A protein binds to PI3K, consequently activating AKT and potentially contributing to the development of $\operatorname{HCC}(22,23)$.
One study identified that HCV rapidly and transiently activated AKT in the early stage of infection via the interaction between the HCV E2 envelope protein and its co-receptors CD81 and claudin-1, with the effect of enhancing viral entry into the cell (24). 
A

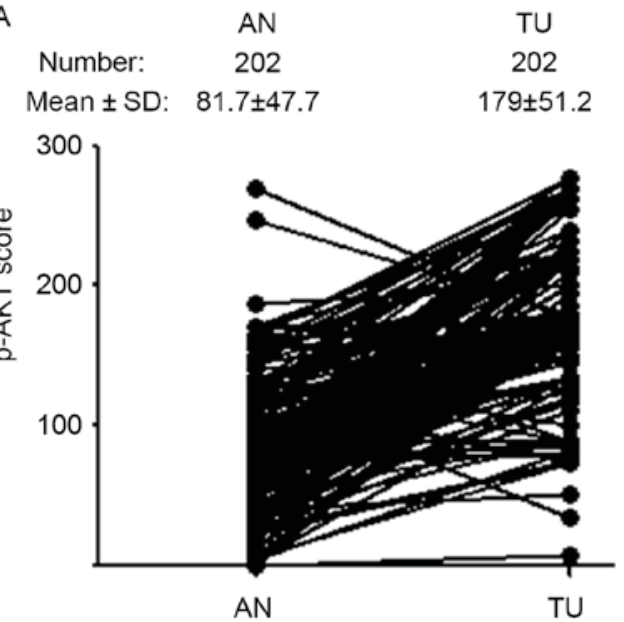

B

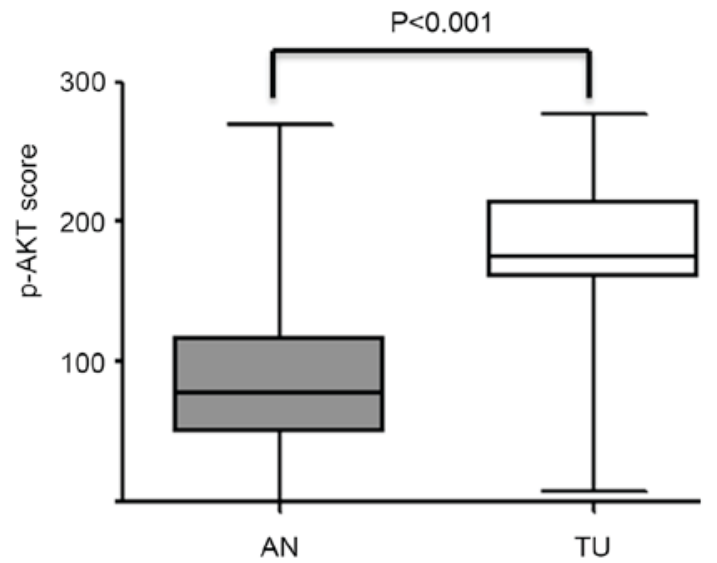

Figure 2. Comparison of p-AKT expression in TU and AN. (A) p-AKT IHC scores were calculated for TU and paired AN tissues. (B) Mean p-AKT IHC scores were compared in TU and paired AN tissues. p-AKT, phosphorylated AKT; TU, tumor; AN, adjacent normal liver; IHC, immunohistochemistry.
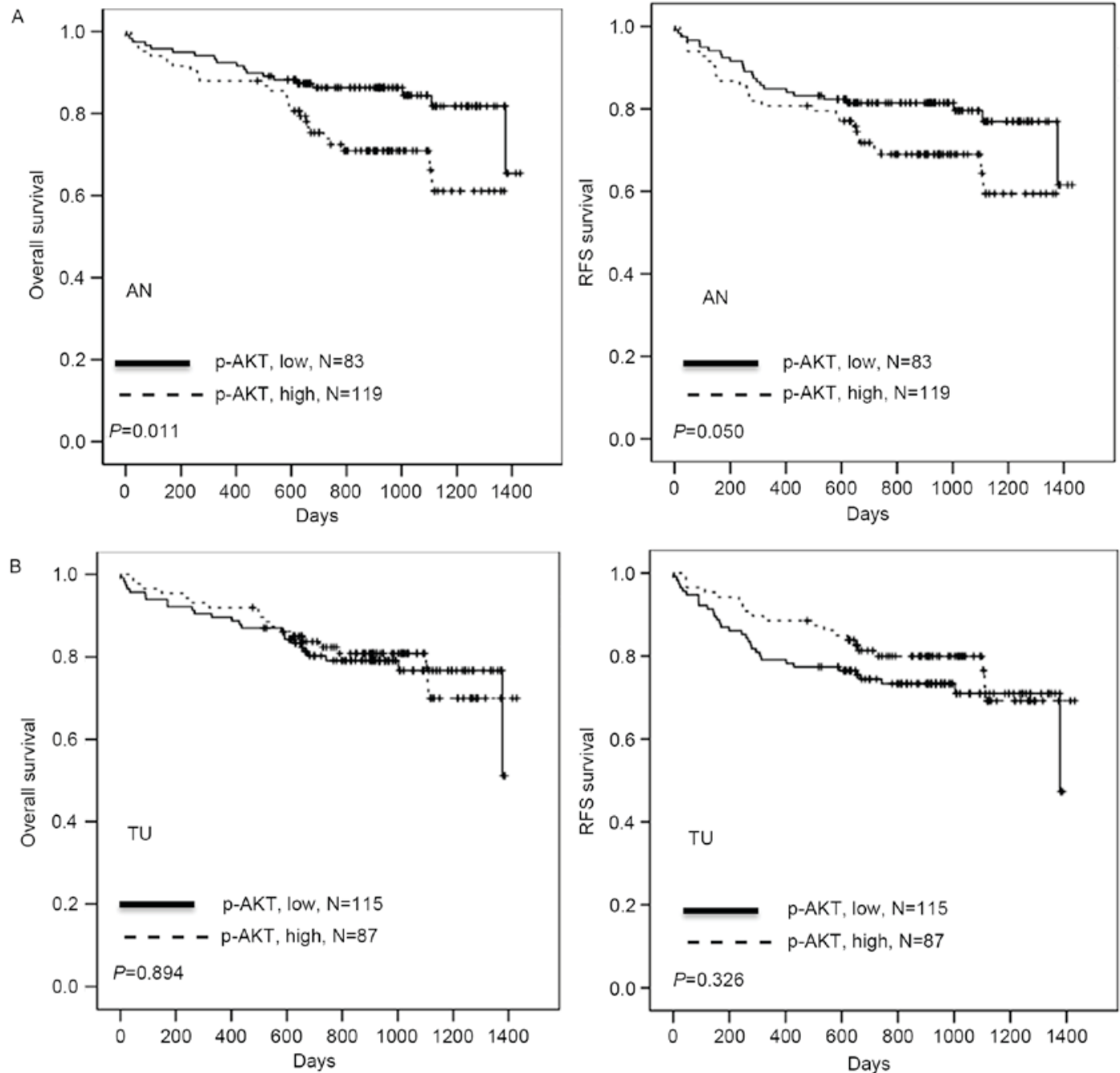

Figure 3. Kaplan-Meier analysis of the association of p-AKT (AN) and (TU) expression with OS and RFS time in patients with HCC. (A) The effect of low vs. high p-AKT (AN) expression in patients with HCC on OS and RFS time. (B) The effect of low vs. high p-AKT (TU) expression in patients with HCC on OS and RFS time. p-AKT (AN), phosphorylated AKT in adjacent normal liver tissue; p-AKT (TU), phosphorylated AKT in tumor tissue; OS, overall survival; RFS, relapse-free survival; HCC, hepatocellular carcinoma.

Another study reported that cancer stem cells or tumor-initiating cells that retain a stem cell-like phenotype, along with the
HCV-induced reprogramming of liver cells, may contribute to hepatocarcinogenesis in an animal model (25). AKT serves an 
additional role in the maintenance of stem-like characteristics, the mesenchymal phenotype and the self-renewal of these cells via the AKT/Forkhead box O/Bcl2-like 11 pathway (26). Therefore, the observation that higher p-AKT (AN) may be an independent prognostic factor for HCC may be due to HCV infection.

In summary, the present study revealed that patients with HCC with high levels of p-AKT (AN) expression exhibited a relatively poor survival rate, and p-AKT (TU) was significantly higher than p-AKT (AN). Curing HCV and inhibiting p-AKT may be necessary to improve the outcome for patients with HCC.

\section{Acknowledgements}

The present study was supported by grant nos. 102-2321B-750-001-MY3 and 103-2314-B-442-002-MY3 from the Ministry of Science and Technology, Taiwan, and nos. RB15001 and RB16001 from Show Chwan Memorial Hospital, Taiwan.

\section{References}

1. Jemal A, Bray F, Center MM, Ferlay J, Ward E and Forman D: Global cancer statistics. CA Cancer J Clin 61: 69-90, 2011.

2. El-Serag HB: Hepatocellular carcinoma. N Engl J Med 365: 1118-1127, 2011.

3. Berasain C, Castillo J, Perugorria MJ, Latasa MU, Prieto J and Avila MA: Inflammation and liver cancer: New molecular links. Ann N Y Acad Sci 1155: 206-221, 2009.

4. Leng J, Han C, Demetris AJ, Michalopoulos GK and Wu T: Cyclooxygenase-2 promotes hepatocellular carcinoma cell growth through Akt activation: Evidence for Akt inhibition in celecoxib-induced apoptosis. Hepatology 38: 756-768, 2003.

5. Yang Y, Guo Y, Tan S, Ke B, Tao J, Liu H, Jiang J, Chen J, Chen G and $\mathrm{Wu} \mathrm{B}$ : $\beta$-Arrestin1 enhances hepatocellular carcinogenesis through inflammation-mediated Akt signalling. Nat Commun 6: $7369,2015$.

6. Vivanco I and Sawyers CL: The phosphatidylinositol 3-Kinase AKT pathway in human cancer. Nat Rev Cancer 2: 489-501, 2002.

7. Uegaki K, Kanamori Y, Kigawa J, Kawaguchi W, Kaneko R, Naniwa J, Takahashi M, Shimada M, Oishi T, Itamochi H and Terakawa N: PTEN-positive and phosphorylated-Akt-negative expression is a predictor of survival for patients with advanced endometrial carcinoma. Oncol Rep 14: 389-392, 2005.

8. Hager M, Haufe H, Kemmerling R, Hitzl W, Mikuz G, Moser PL and Kolbitsch C: Increased activated Akt expression in renal cell carcinomas and prognosis. J Cell Mol Med 13: 2181-2188, 2009.

9. Malinowsky K, Nitsche U, Janssen KP, Bader FG, Späth C, Drecoll E, Keller G, Höfler H, Slotta-Huspenina J and Becker KF: Activation of the PI3 K/AKT pathway correlates with prognosis in stage II colon cancer. Br J Cancer 110: 2081-2089, 2014.

10. Tokunaga E, Kimura Y, Oki E, Ueda N, Futatsugi M, Mashino K, Yamamoto M, Ikebe M, Kakeji Y, Baba H and Maehara Y: Akt is frequently activated in HER2/neu-positive breast cancers and associated with poor prognosis among hormone-treated patients. Int J Cancer 118: 284-289, 2006.
11. Dai DL, Martinka M and Li G: Prognostic significance of activated Akt expression in melanoma: A clinicopathologic study of 292 cases. J Clin Oncol 23: 1473-1482, 2005.

12. Wang W, Wen Q, Xu L, Xie G, Li J, Luo J, Chu S, Shi L, Huang D, $\mathrm{Li} \mathrm{J}$ and Fan S: Activation of Akt/mTOR pathway is associated with poor prognosis of nasopharyngeal carcinoma. PLoS One 9: e106098, 2014.

13. Zhang Y, Guo X, Yang M, Yu L, Li Z and Lin N: Identification of AKT kinases as unfavorable prognostic factors for hepatocellular carcinoma by a combination of expression profile, interaction network analysis and clinical validation. Mol Biosyst 10: 215-222, 2014.

14. Gedaly R, Angulo P, Chen C, Creasy KT, Spear BT, Hundley J, Daily MF, Shah M and Evers BM: The role of PI3K/mTOR inhibition in combination with sorafenib in hepatocellular carcinoma treatment. Anticancer Res 32: 2531-2536, 2012.

15. Simioni C, Martelli AM, Cani A, Cetin-Atalay R, McCubrey JA, Capitani S and Neri LM: The AKT inhibitor MK-2206 is cytotoxic in hepatocarcinoma cells displaying hyperphosphorylated AKT-1 and synergizes with conventional chemotherapy. Oncotarget 4: 1496-1506, 2013.

16. Zhai B, Hu F, Jiang X, Xu J, Zhao D, Liu B, Pan S, Dong X, Tan G, Wei Z, et al: Inhibition of Akt reverses the acquired resistance to sorafenib by switching protective autophagy to autophagic cell death in hepatocellular carcinoma. Mol Cancer Ther 13: 1589-1598, 2014.

17. Edge SB and Compton CC: The American joint committee on cancer: The 7th edition of the AJCC cancer staging manual and the future of TNM. Ann Surg Oncol 17: 1471-1474, 2010.

18. Yu HC, Hung MH, Chen YL, Chu PY, Wang CY, Chao TT, Liu CY, Shiau CW and Chen KF: Erlotinib derivative inhibits hepatocellular carcinoma by targeting CIP2A to reactivate protein phosphatase 2A. Cell Death Dis 5: e1359, 2014.

19. Ahmad SA, Bilimoria MM, Wang X, Izzo F, Delrio P, Marra P, Baker TP, Porter GA, Ellis LM, Vauthey JN, et al: Hepatitis B or $\mathrm{C}$ virus serology as a prognostic factor in patients with hepatocellular carcinoma. J Gastrointest Surg 5: 468-476, 2001.

20. de Oliveria Andrade LJ, D'Oliveira A, Melo RC, De Souza EC, Costa Silva CA and Paraná R: Association between hepatitis C and hepatocellular carcinoma. J Glob Infect Dis 1: 33-37, 2009.

21. Douam F, Ding Q and Ploss A: Recent advances in understanding hepatitis C. F1000Res 3: 5. pii: F1000 Faculty Rev-131, 2016.

22. Street A, Macdonald A, Crowder K and Harris M: The Hepatitis C virus NS5A protein activates a phosphoinositide 3-kinase-dependent survival signaling cascade. J Biol Chem 279: 12232-12241, 2004.

23. Street A, Macdonald A, McCormick C and Harris M: Hepatitis C virus NS5A-mediated activation of phosphoinositide 3-kinase results in stabilization of cellular beta-catenin and stimulation of beta-catenin-responsive transcription. J Virol 79: 5006-5016, 2005.

24. Liu Z, Tian Y, Machida K, Lai MM, Luo G, Foung SK and Ou JH: Transient activation of the PI3K-AKT pathway by hepatitis $\mathrm{C}$ virus to enhance viral entry. J Biol Chem 287: 41922-41930, 2012.

25. Ali N, Allam H, May R, Sureban SM, Bronze MS, Bader T, Umar S, Anant S and Houchen CW: Hepatitis C virus-induced cancer stem cell-like signatures in cell culture and murine tumor xenografts. J Virol 85: 12292-12303, 2011.

26. Gargini R, Cerliani JP, Escoll M, Antón IM and Wandosell F: Cancer stem cell-like phenotype and survival are coordinately regulated by Akt/FoxO/Bim pathway. Stem Cells 33: 646-660, 2015. 